\title{
ANÁLISE DO USO E COBERTURA DA TERRA EM DECORRÊNCIA DA EXPANSÃO DO CULTIVO DE EUCALIPTO NO MUNICÍPIO DE SELVÍRIA/MS
}

Angélica Estigarribia São Miguel ${ }^{1}$, Rafael Brugnolli Medeiros ${ }^{2}$, Wallace de Oliveira ${ }^{3}$ (1 - Universidade Federal do Mato Grosso do Sul, Mestre em Geografia, angelica.estigarribia@hotmail.com, 2 - Universidade Federal da Grande Dourados, Doutorando em Geografia, rafael_bmedeiros@hotmail.com, 3 - Universidade Federal do Mato Grosso do Sul, docente, Doutor em Geografia, wallace.oliveira@ hotmail.com)

Resumo: O presente trabalho tem como objetivo, elaborar uma análise de uso e cobertura vegetal no município de Selvíria/BRASIL, que possui uma área de $3256,25 \mathrm{~km}^{2}$. Para a preparação da pesquisa foi elaborado um mapeamento da evolução do uso e cobertura da terra nos anos de 2000, 2008 e 2014. Para o mapeamento, foram utilizadas imagens do satélite Landsat $5 \mathrm{TM}$, processadas com o auxilio do software SPRING 5.0.6 - INPE e Landsat 8 OLI, conforme classificação proposta pelo manual de uso e ocupação da terra do IBGE (2013). Como resultados, observaram-se rápidas transformações da paisagem devido à expansão do setor florestal que vem acompanhada da substituição da vegetação existente na região por pastagens e cultivo de eucalipto. Concluiu-se que o município de Selvíria/BRASIL está se tornando um atrativo de grandes empresas para o cultivo de florestas plantadas, hoje contando com grandes empresas deste setor e de forma geral, esse cultivo tem adentrado várias áreas como de pastagens e áreas florestais.

Palavras Chave: geoprocessamento; cultivo de eucalipto; transformação da paisagem.

\section{ANALYSIS OF USE AND LAND COVER ARISING OUT OF EUCALYPTUS CULTIVATION EXPANSIONIN THE MUNICIPALITY OF SELVÍRIA/BRAZIL}

\begin{abstract}
This work has the most objective draw up a usage analysis of use and land cover in municipality of Selvíria/BRAZIL, which has an area of $3256,25 \mathrm{~km}^{2}$. For the preparation of the research was designed to map the evolution of use and land cover in 2000, 2008 and 2014. For the mapping were used Landsat 5 satellite images, processed with the help of SPRING
\end{abstract}

Artigo recebido para publicação em 14 de Junho de 2016

Artigo aprovado para publicação em 11 de Dezembro de 2016 


\section{GEOAMBIENTE ON-LINE \\ Revista Eletrônica do Curso de Geografia - UFG/REJ \\ Graduação e Pós-Graduação em Geografia \\ http://revistas.ufg.br/index.php/geoambiente/index \\ Apoio: PRPG/PROAPUPEC \\ Jataí-GO | n.27 | Jul-Dez/2016}

5.0.6 software - INPE and Landsat 8, as classified by the use of manual and occupation of the land IBGE (2013). As preliminary results are observed rapid landscape changes due to the expansion of the forestry industry that is accompanied by the replacement of the existing vegetation in the area for pastures and eucalyptus cultivation. It was concluded that the municipality of Selvíria/BRAZIL is becoming an attractive large companies for the cultivation of planted forests, now relying on large companies in this sector and in general, this crop has several areas such as grassland and areas forest.

Keywords: Geoprocessing; eucalyptus cultivation; landscape transformation.

\section{ANÁLISIS DE USO Y CUBIERTAS DE LA TIERRA PROVENGAN DEL EXPANSIÓN DE CULTIVO DE EUCALIPTO EN EL MUNICIPIO SELVÍRIA/BRASIL}

Resumen: Este trabajo tiene el objetivo de desarrollar un mayor análisis de uso de la ocupación del suelo y la vegetación de municipio de Selvíria/BRASIL, que tiene una superficie de $3256,25 \mathrm{~km}^{2}$. Para la preparación de la encuesta fue diseñada para trazar la evolución del uso y cobertura del suelo en 2000, 2008 y 2014. Para el mapeo se utilizaron Landsat 5 imágenes por satélite, procesados con la ayuda de software 5.0.6 PRIMAVERA INPE y Landsat 8, según la clasificación del uso del manual y la ocupación de la tierra IBGE (2013). Como resultados preliminares se observan cambios rápidos del paisaje debido a la expansión de la industria forestal que se acompaña de la sustitución de la vegetación existente en la zona de pastos y cultivos de eucalipto. Se concluyó que el municipio de Selvíria/BRASIL se está convirtiendo en un atractivo grandes empresas para el cultivo de bosques plantados, ahora depender de las grandes empresas de este sector y, en general, este cultivo tiene adentrado varias áreas tales como praderas y áreas de los bosques.

Palabras Clave: geoprocesamiento; cultivo de eucaliptus; la transformación del paisaje.

\section{INTRODUÇÃO}

O homem desenvolveu uma ampla capacidade de se adaptar e transformar o meio onde habita, sendo que o mesmo não obtém conhecimento a respeito das limitações desse território, que por sua vez, vem sendo utilizado de forma descontrolada e desmedida, causando modificações nocivas à própria sociedade e aos ambientes naturais.

De acordo com as transformações ocasionadas no meio, é possível evidenciar diferentes paisagens modificadas pelo homem. A paisagem que vemos hoje é retrato dos 


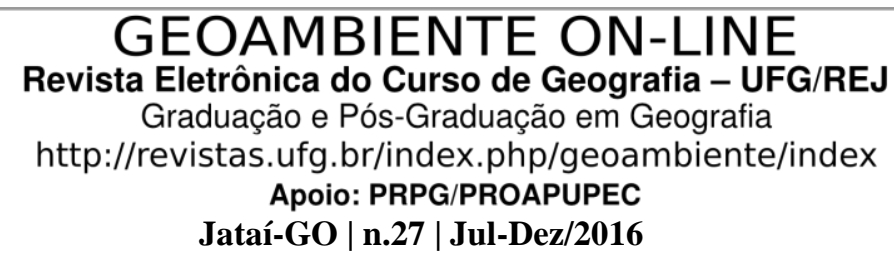

acontecimentos do passado e consequentemente não será a mesma do futuro (SANTOS, 2007), passando por evolução têmporo-espacial significativa.

Partindo para a necessidade de se entender o passado, abrangendo suas características, a fim de obter um retrato do futuro e de possíveis cenários que serão alcançados nestes ambientes, a proposta desta pesquisa se enquadra nesta discussão, pois, mediante a análise multitemporal, é possível analisar de que forma se deram as ocupações e como as mesmas vem avançando ao longo dos anos sobre áreas em que necessitam ser melhores preservadas e/ou conservadas.

Neste sentido, Gregory (1992) afirma que o estudo do passado é imprescindível na tentativa de predizer uma tendência, levando em conta a investigação atual, auxiliando na compreensão de como este ambiente evoluirá no futuro. Para isso, é importante o entendimento da estruturação destes ambientes, seu comportamento, pois vai predizer diversas questões que poderão ser constatadas na análise ambiental, bem como, alterações futuras para estes cenários.

O cultivo de eucalipto em grande escala, acabou sendo utilizado no leste de Mato Grosso do Sul, devido à diversas questões econômicas e ambientais. Desde o incentivo fiscal, destinado à estas empresas, até seu arcabouço ambiental, como a abundância de recursos hídricos, ao solo e ao relevo, que acabam favorecendo seu plantio e mecanização.

Em seu processo histórico, o eucalipto é uma árvore nativa da Austrália, do Timor e da Indonésia. Os primeiros plantios dessa espécie foram realizados no início do século XVIII na Europa, Ásia e África. A partir do século XIX começou a ser cultivado também nos países da América do Sul (PRYOR, 1976). No século XIX os Estados Unidos passou a ser o maior produtor deste setor, porém, investiram na produção de papel para embalagens. Após a Segunda Guerra Mundial, Rússia e China passaram a ter grandes reservas florestais. No entanto este fato criou animosidades entre os países industrializados que viam na ascensão do mercado russo e chinês, um perigo ao controle ocidental sobre a produção de matéria prima florestal (BINKOWSKI, 2009).

O eucalipto foi introduzido no sul da Europa e em algumas das colônias européias, em meados do século XIX, foi tido em grande consideração (RADICH, 1994). Em Portugal, onde a sua entrada se fez em 1854 (COUTINHO, 1886) ou 1859 (PIMENTEL, 1884), e noutras regiões de clima mediterrânico ou subtropical havia uma crônica falta de madeira, o eucalipto constituía uma fonte fácil e acessível, devido seu crescimento rápido, se tornando um meio eficaz de fornecer madeira para uso nas explorações agrícolas e combustível (ALVES, 2007). 


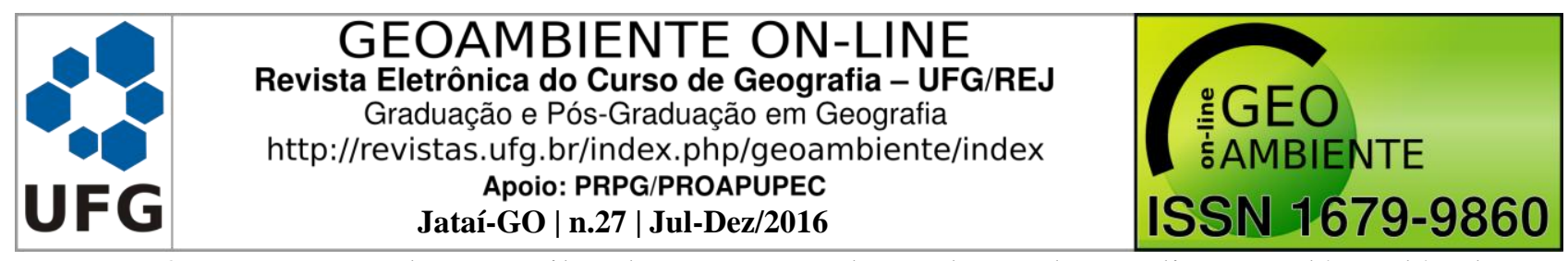

O contexto atual no Brasil, sobre o avanço da produção de eucalipto, se dá na década de 60 e 70 devido à introdução de alguns incentivos fiscais para a aplicação no mercado acionário, dentre os quais se destacam o Fundo 157, criados pelo Decreto Lei $\mathrm{n}^{\circ}$ 157, de 10/02/1967. O Fundo 157 era uma opção fornecida aos contribuintes de utilizar parte do imposto de renda em aquisição de quotas de fundos administrados por instituições financeiras de livre escolha do aplicador (PORTAL DO INVESTIDOR, s/d).

Entretanto, o aumento nas áreas de plantio do eucalipto e o crescimento de empresas que trabalham neste setor, como as de celulose e papel, têm fortalecido os questionamentos feitos em relação à ocupação de terras e os impactos que estes empreendimentos podem gerar em aspectos sociais, econômicos e ambientais.

O reflorestamento com eucalipto em grandes extensões territoriais tem sido alvo de caloroso debate, que está longe de ser consensual, ainda mais quando se inclui a questão ambiental como central e imprescindível para o desenvolvimento sustentável (VIANA, 2004).

Diante disto, o que se observa é uma excessiva pressão do sistema produtivo sobre os recursos naturais, buscando a obtenção de matéria prima que é empregada na produção de bens, sendo utilizados no crescimento econômico. Esse desenvolvimento gera capital, mas em contrapartida, além de rejeitos e efluentes, gera uma degradação ao meio ambiente, muito dos quais irreversíveis (ALMEIDA et al. 1993).

Segundo Oliveira (2012), esse desenvolvimento econômico por sua vez, tem se mostrado influenciado pelo avanço tecnológico e informativo. A partir desses avanços, indústrias do setor privado levam em consideração em seus processos produtivos os custos gerados sobre seus produtos acabados, a exemplo disso são as empresas que para um menor gasto e maior lucratividade, estão se instalando em locais estratégicos, visando ficarem mais próximas de suas matérias-primas e/ou recursos naturais.

Com o crescimento e aumento de produções para atender as necessidades humanas, novas formas de plantio e produção industrial foram estabelecidas, ocasionando o aumento crescente de poluentes, modificação da paisagem e fragmentação de ecossistemas. Essas modificações ocorrem sobre uma área bastante ampla, abrangendo toda a região leste do Estado.

Entretanto para esta pesquisa optou-se por fazer um recorte territorial correspondente ao município de Selvíria/BRASIL, permitindo assim uma análise local, do avanço da monocultura do eucalipto. Esta pesquisa tem como objetivo principal avaliar as alterações no uso e cobertura da terra, nos anos de 2000, 2008 e 2014, causadas em decorrência da expansão do cultivo de eucalipto. 


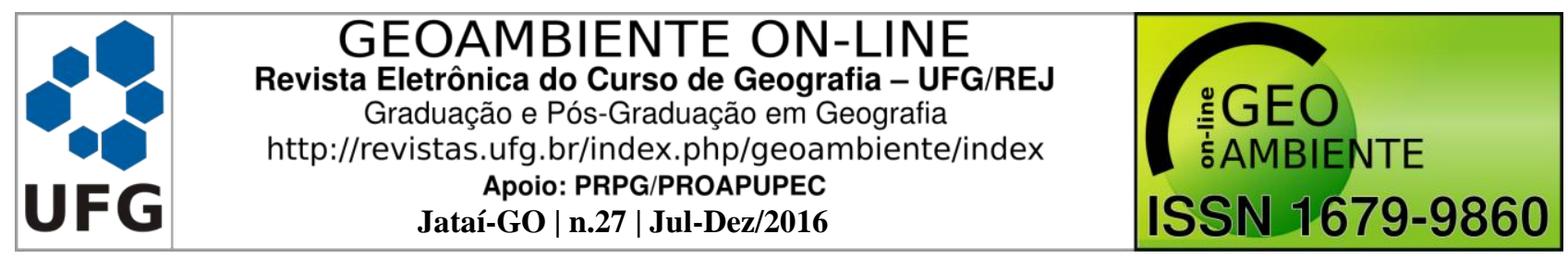

Portanto, neste estudo objetivou-se mapear e criar um banco de dados sobre a dinâmica das alterações no uso da terra e da cobertura vegetal em três anos de análise (2000, 2008 e 2014), correspondente ao município de Selvíria/BRASIL, lozalizado a leste do estados de Mato Grosso do Sul, está inserido entre as coordenadas geográficas $20^{\circ} 40^{\prime} 00^{\prime}$ S e $19^{\circ} 57^{\prime} 20^{\prime \prime} \mathrm{S}$ e $52^{\circ} 10^{\prime} 00^{\prime \prime} \mathrm{O}$ e 51³0’40” O, os rios que margeiam o município é o Rio Paraná e o Rio Sucuriú, como mostra a Figura 1.

Figura 1: Mapa de localização do município de Selvíria/BRASIL

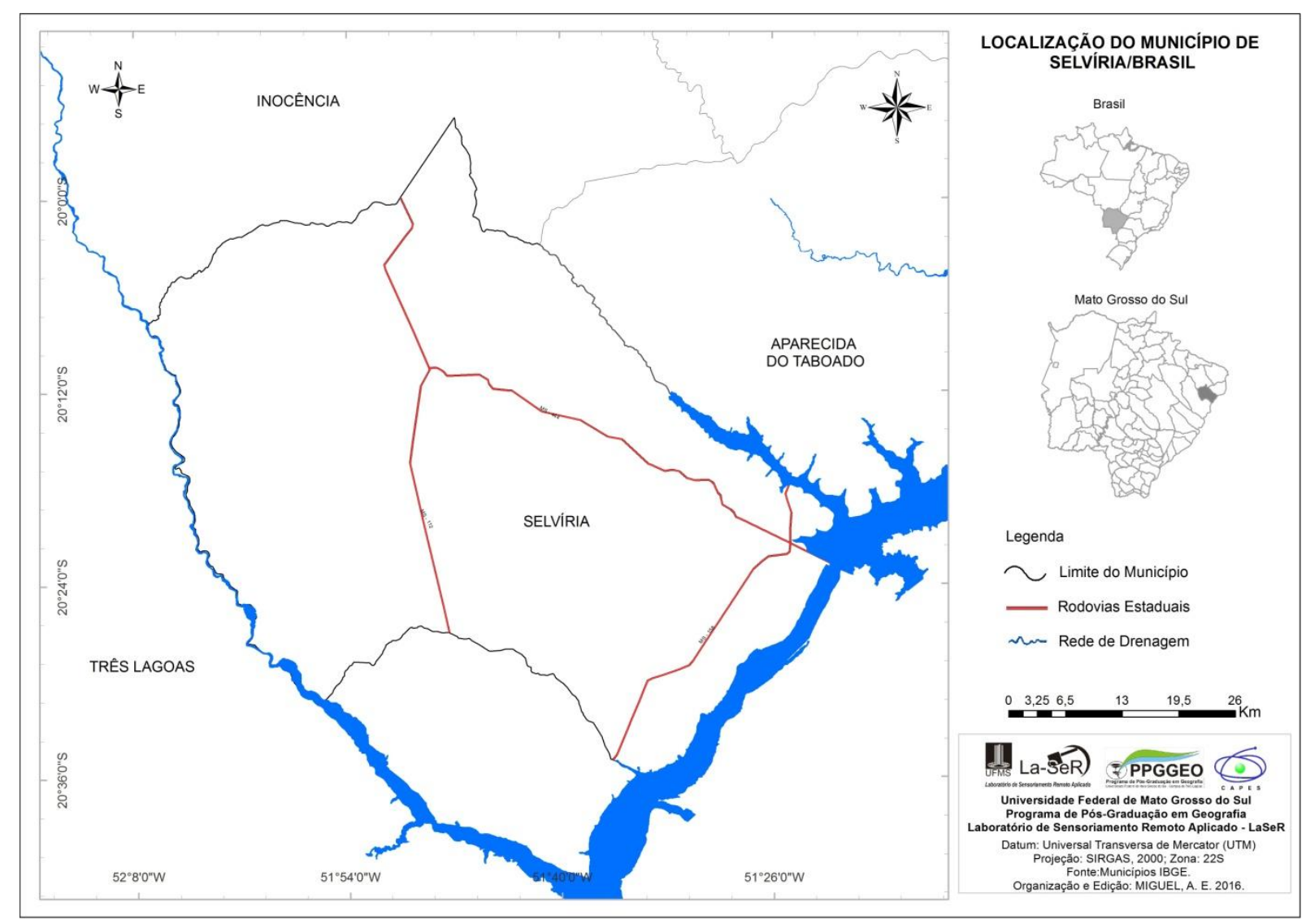

\section{METODOLOGIA}

Os procedimentos metodológicos do uso e cobertura da terra, foram realizados a partir da criação de um banco de dados em ambiente SIG (Sistemas de Informações Geográficas). Os programas utilizados foram o SPRING® 5.2.7 para a manipulação das imagens orbitais até a fase de classificação e o programa ArcGIS® 10 para finalização dos mapas temáticos.

O Sistema de Processamento de Informações Georreferenciadas (SPRING®), foi desenvolvido pelo Instituto Nacional de Pesquisas Espaciais (INPE), visando à manipulação de dados geográficos, em especial, manipulação de Imagens adquiridas via sensoriamento remoto (SILVA, 2013). 


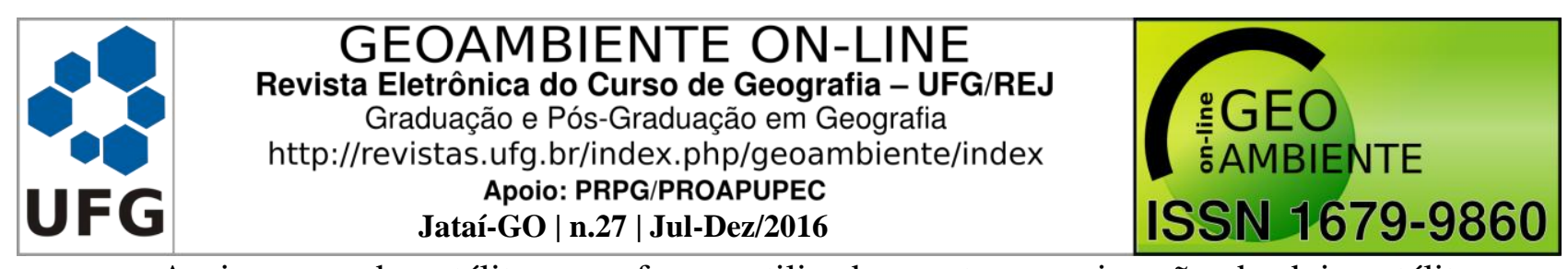

As imagens de satélites que foram utilizadas nesta pesquisa são de dois satélites, ambos Land Remote Sensing Satellite - Landsat, porém, para o ano de 2000 e 2008 utilizou-se o Landsat 5 com sensor TM - Thematic Mapper, que segundo informações extraídas do Serviço Geológico dos Estados Unidos - USGS, foi desenvolvido pela National Aeronautics and Space Administration - NASA, sendo este, o quinto satélite deste programa.

Nas análises de 2014 foi utilizado o Landsat 8, que possui diversas melhorias, satélite este, que segundo Serviço Geológico dos Estados Unidos - USGS, se encontra a uma altitude de $705 \mathrm{~km}$, com dois sensores, porém o que foi utilizado nesta pesquisa é o Operacional Land Imager - OLI, com um resolução de 30 metros, apenas uma exceção, que é a banda 8, que possui 15 metros de resolução espacial, utilizada para o mapeamento. As imagens Landsat8 são entregues em 16 Bits e alguns programas não são capazes de fazer a leitura, sendo necessário realizar um rescale (Conversão Radiométrica) para 8 bits.

Os dados armazenados em um banco de dados respeitam as regras da aplicação, definidas pelas restrições de integridade, para a elaboração do uso da terra e cobertura vegetal foi realizado uma interpretação de imagens de satélite Landsat 5 sensor TM, bandas 3, 4 e 5 do mês de agosto dos anos de 2000 e 2008 adquiridas gratuitamente no site do INPE Instituto Nacional de Pesquisas Espaciais e do satélite Landsat 8 sensor OLI, bandas 4, 5 e 6 do ano de 2014, disponibilizadas através do site do Serviço Geológico dos Estados Unidos USGS.

No Spring um Banco de Dados corresponde a um diretório onde são armazenados todos os dados necessários para cada projeto, e esses projetos são armazenados em subdiretórios (SILVA, 2013). As definições das classes do uso e cobertura da terra dos três diferentes anos foram: cultivo de eucalipto, lavouras, área florestal, pastagem, área descoberta, área urbanizada, solo úmido e água.

$\mathrm{Na}$ classe temática cultivos de eucalipto foram adquiridos amostra de toda área destinada ao plantio de eucalipto. As classes lavouras referem-se às áreas de lavouras temporárias de plantio de cana de açúcar e outras culturas. A classe temática área florestal é referente às áreas de reserva legal e matas ciliares. Na classe temática pastagem foi caracterizada pela presença de gramíneas destinadas a criação do gado de corte ou apenas pastagem. Na categoria área urbanizada foi delimitado a cidade de Selvíria/BRASIL. Com relação à classe de solo úmido, são áreas de várzeas ou pontos de alagamentos, sendo encontrada ao longo de todas as áreas próximas dos cursos d'água.

Por fim a imagem classificada no Spring foi importada para o ArcGis ${ }^{\circledR}$ 10, para elaboração do layout do mapa, na interpretação de imagens de satélites diversos fatores 


\section{GEOAMBIENTE ON-LINE}

Revista Eletrônica do Curso de Geografia - UFG/REJ

Graduação e Pós-Graduação em Geografia

http://revistas.ufg.br/index.php/geoambiente/index

Apoio: PRPG/PROAPUPEC

Jataí-GO | n.27 | Jul-Dez/2016

devem ser levados em consideração como, por exemplo, o nível de experiência do analista, as características das bandas utilizadas pelo satélite utilizado no imageamento e principalmente, o conhecimento da área de estudo. $\mathrm{Na}$ verdade, quanto maior é o conhecimento sobre a área de estudo, maior é a qualidade de informações que podem obter (FLORENZANO, 2007, p.43).

\section{RESULTADOS}

O mapeamento do uso e cobertura da terra é uma importante análise do espaço geográfico devido à possibilidade de espacializar e quantificar os diferentes tipos de usos que existem nesta área. Para sua análise, no município de Selvíria/MS, baseou-se no processamento e interpretação das imagens dos satélites Landsat 5/TM e Landsat 8/OLI nos anos de 2000, 2008 e 2014, identificando classes temáticas: cultivo de eucalipto, lavouras, área florestal, pastagem, área descoberta, solo úmido, área urbanizada e corpos d'água, seguindo com algumas adaptações, as classes do IBGE (2015).

Estas modificações foram necessárias devido ao objetivo principal da pesquisa, que é analisar a expansão do cultivo de eucalipto nestas áreas, e suas cores foram modificadas buscando uma melhor visualização das classes no mapeamento.

Com base nesta premissa, os mapeamentos demonstram os tipos de uso e cobertura da terra no município de Selvíria/BRASIL, nos anos de 2000, 2008 e 2014, (Figura 2). Já a Tabela 1 refere-se aos dados das áreas de cada uso e cobertura da terra, gerados pelo ArcGis ${ }^{\circledR}$, em $\left(\mathrm{km}^{2}\right)$ e porcentagens $(\%)$.

As Áreas Florestais, representadas por matas ciliares e áreas de reservas, em Selvíria alcançou 886,74km² em 2000, com uma constante redução constante até o ano de 2014, chegando a 742,69 .

A classe Área Urbanizada, apresentou uma elevação durante os anos, obedecendo a uma tendência nos dias atuais, passando de $6,48 \mathrm{~km}^{2}$ para $8,12 \mathrm{~km}^{2}$, nos anos de 2000 e 2014 respectivamente. Por esta cidade não apresentar grande população, esse aumento ainda é em pequena escala.

Os Corpos d'Água neste município estão representados pelo rio Paraná na região leste e na região sul e também abrangeu pequena parte do rio Sucuriú, favorecendo a identificação

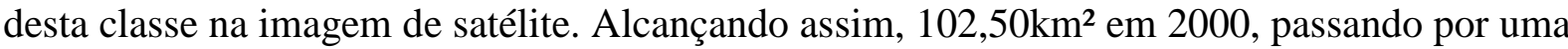
ligeira redução em 2008 e uma redução pouco maior para o ano de 2014, chegando a $97,74 \mathrm{~km}^{2}$. 
Figura 2: Mapa de Uso e Cobertura da Terra no Município de Selvíria/BRASIL, nos anos de 2000, 2008 e 2014.

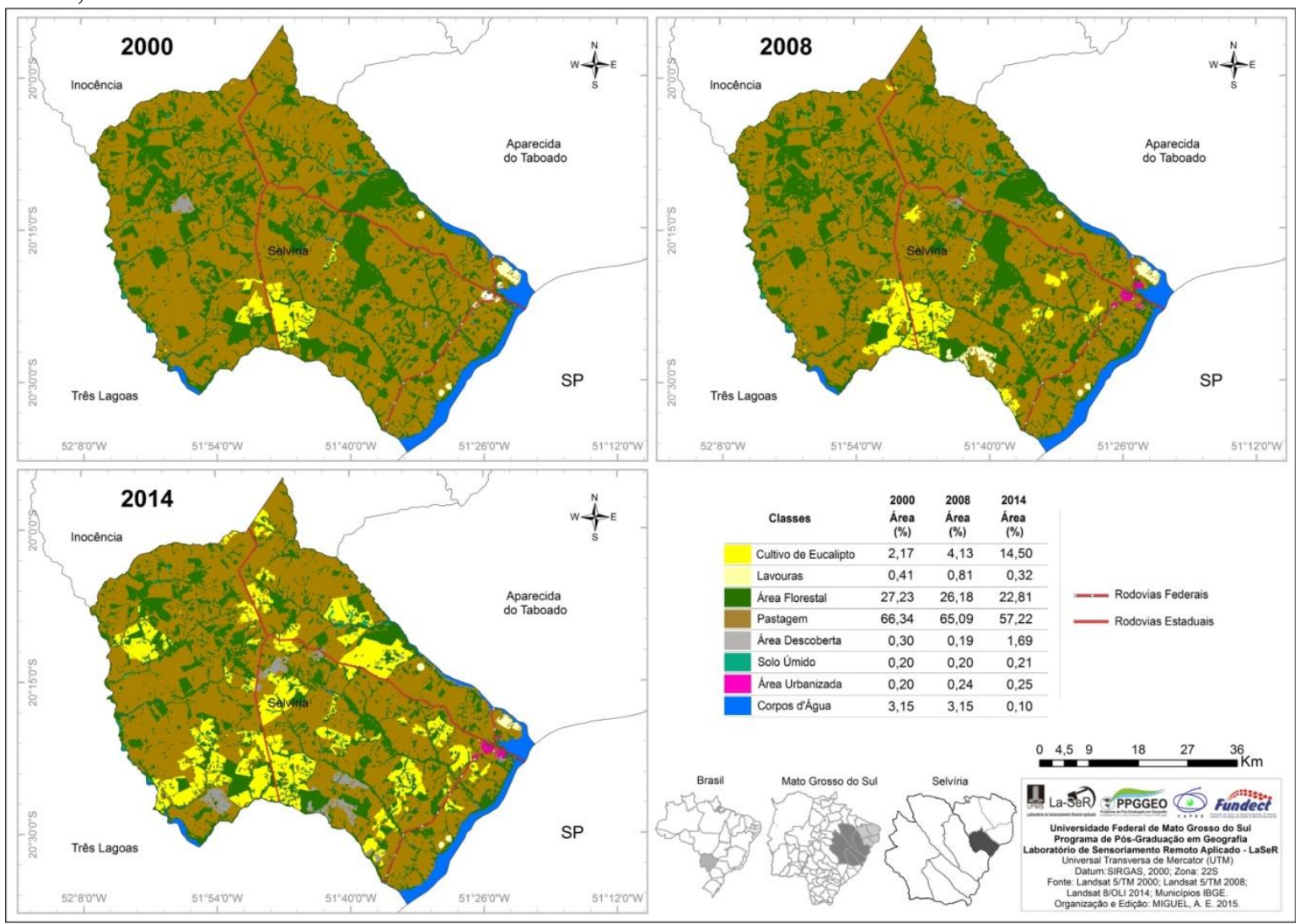

Tabela 1: Evolução do Uso e Cobertura da Terra no Município de Selvíria/ BRASIL, nos anos de 2000, 2008 e 2014.

\begin{tabular}{|c|c|c|c|}
\hline \multirow[b]{2}{*}{ Classes } & 2000 & 2008 & 2014 \\
\hline & $\begin{array}{l}\text { Área } \\
\left(\mathbf{k m}^{2}\right)\end{array}$ & $\begin{array}{l}\text { Área } \\
\left(\mathbf{k m}^{2}\right)\end{array}$ & $\begin{array}{l}\text { Área } \\
\left(\mathbf{k m}^{2}\right)\end{array}$ \\
\hline Área Descoberta & 9,66 & 6,25 & 55,17 \\
\hline Área Florestal & 886,74 & 852,53 & 742,69 \\
\hline Área Urbanizada & 6,48 & 7,88 & 8,12 \\
\hline Corpos d'Água & 102,50 & 102,47 & 97,74 \\
\hline Cultivo de Eucalipto & 70,77 & 134,45 & 472,28 \\
\hline Lavouras & 13,25 & 26,48 & 10,29 \\
\hline Pastagem & 2160,30 & 2119,64 & 1863,09 \\
\hline Solo Úmido & 6,55 & 6,55 & 6,87 \\
\hline TOTAL & 3256,25 & 3256,25 & 3256,25 \\
\hline
\end{tabular}

O Cultivo de Eucalipto mostra claramente o constante aumento que obteve durante estes anos, apontando para a necessidade e importância desta pesquisa, pois suas áreas de abrangência expandiram mais de $600 \%$ no período de 14 anos analisados, passando de $70,77 \mathrm{~km}^{2}$ em 2000 para $472,28 \mathrm{~km}^{2}$ em 2014. O cultivo de eucalipto no município é de 


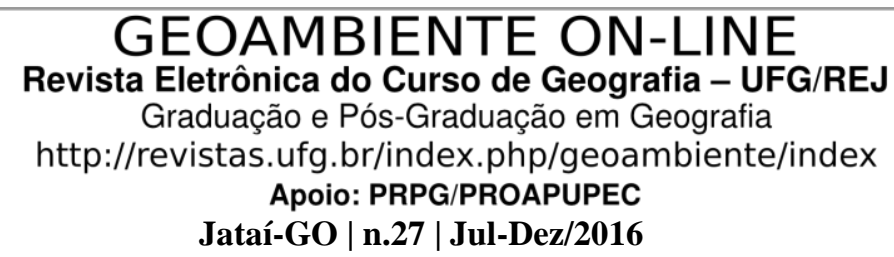

responsabilidade das empresas Fibria-MS e Eldorado Brasil Celulose, ambas localizadas no município de Três Lagoas, sendo áreas próprias, arrendadas e de parceiros, o plantio se concentra nas regiões próximas as rodovias estaduais, devido à facilidade no acesso dos caminhões.

Atualmente as florestas plantadas de eucalipto abrangem uma área de 7,6 milhões de ha em todo Brasil. No caso de Mato Grosso do Sul, o cenário que vem sendo palco do eucalipto é a microrregião de Três Lagoas, que já teve ciclos com a agricultura e pecuária, em um dado momento onde o solo já não poderia mais ser utilizado para tais fins foi propício à introdução das florestas plantadas (KUDLAVICZ, 2011).

Segundo a Associação Brasileira de Celulose e Papel (Bracelpa), em 2006, 61\% das terras reflorestadas para uso industrial pelo setor de papel e celulose estavam concentradas em quatro estados brasileiros: Bahia (340 mil hectares), São Paulo (384 mil hectares), Minas Gerais (176 mil hectares) e Espírito Santo (130 mil hectares). 4 Notadamente, tais regiões concentram as indústrias nacionais à base de madeira: celulose (presente em todos os estados mencionados), papel (mais concentrada no Estado de São Paulo), siderurgia ("guseiros" de Minas Gerais e do Pará), sólidos de madeira e moveleira (presente no Sul e no Triângulo Mineiro, entre outros estados) (VITAL, 2007).

As classes de Áreas Descobertas, que correspondem à falta de vegetação em suas terras, apresentaram em Selvíria, uma área de $9,66 \mathrm{~km}^{2}$ no ano de 2000 , área relativamente pequena se comparado à extensão do município, porém, no ano de 2008 essas áreas reduziram, passando a ocupar $6,25 \mathrm{~km}^{2}$, mas no ano de 2014 , essas áreas apresentaram uma elevação considerável, principalmente, pela introdução do cultivo de eucalipto nestas áreas, que acaba deixando o solo exposto para futuro plantio, com isso, alcançou $55,17 \mathrm{~km}^{2}$, essas áreas recebem um novo plantio como mostra a Figura 3.

As áreas de Lavouras vêm reduzindo com o passar dos anos, porém, em menos quantidade se comparado com as áreas florestais, em 2000 apresentava 13,25km² chegando à $10,29 \mathrm{~km}^{2}$ no ano de 2014. Outra classe que vem sendo reduzida com o passar dos anos, é pastagem, assim como em todos os municípios, esta classe apresenta redução considerável, de 2160,30 em 2000 para 1863,09 $\mathrm{km}^{2}$ no ano de 2014.

Já a classe de Solo Úmido, se encontra nas planícies dos cursos fluviais, porém, ainda em pequenas áreas, com 6,55 no ano de 2000, permanecendo este valor em 2008 e chegando à 6,87 no ano de 2014. Portanto o município de Selvíria mostrou uma alteração significativa com relação à expansão do cultivo de eucalipto nos anos de analise. 


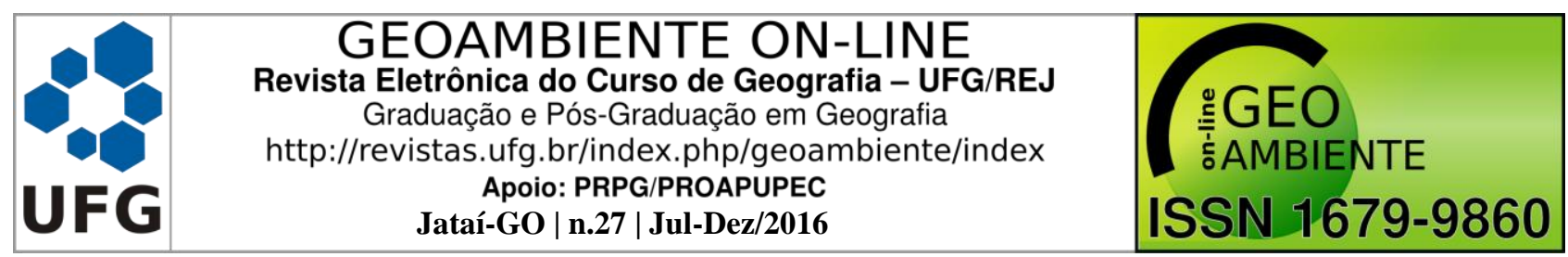

Por fim, os estudos voltados do uso e cobertura da terra possibilitam um detalhamento prévio do meio físico da área estudada. Esse estudo servirá como base para elaboração de novos estudos ambientais, sendo que a análise sobre a expansão do cultivo de eucalipto no estado de Mato Grosso do Sul, ainda se mostra nova, apontando para a necessidade de novas pesquisas.

Figura 3: Ao fundo, o cultivo de Eucalipto em larga escala, em primeiro plano, o replantio de uma área já colhida.

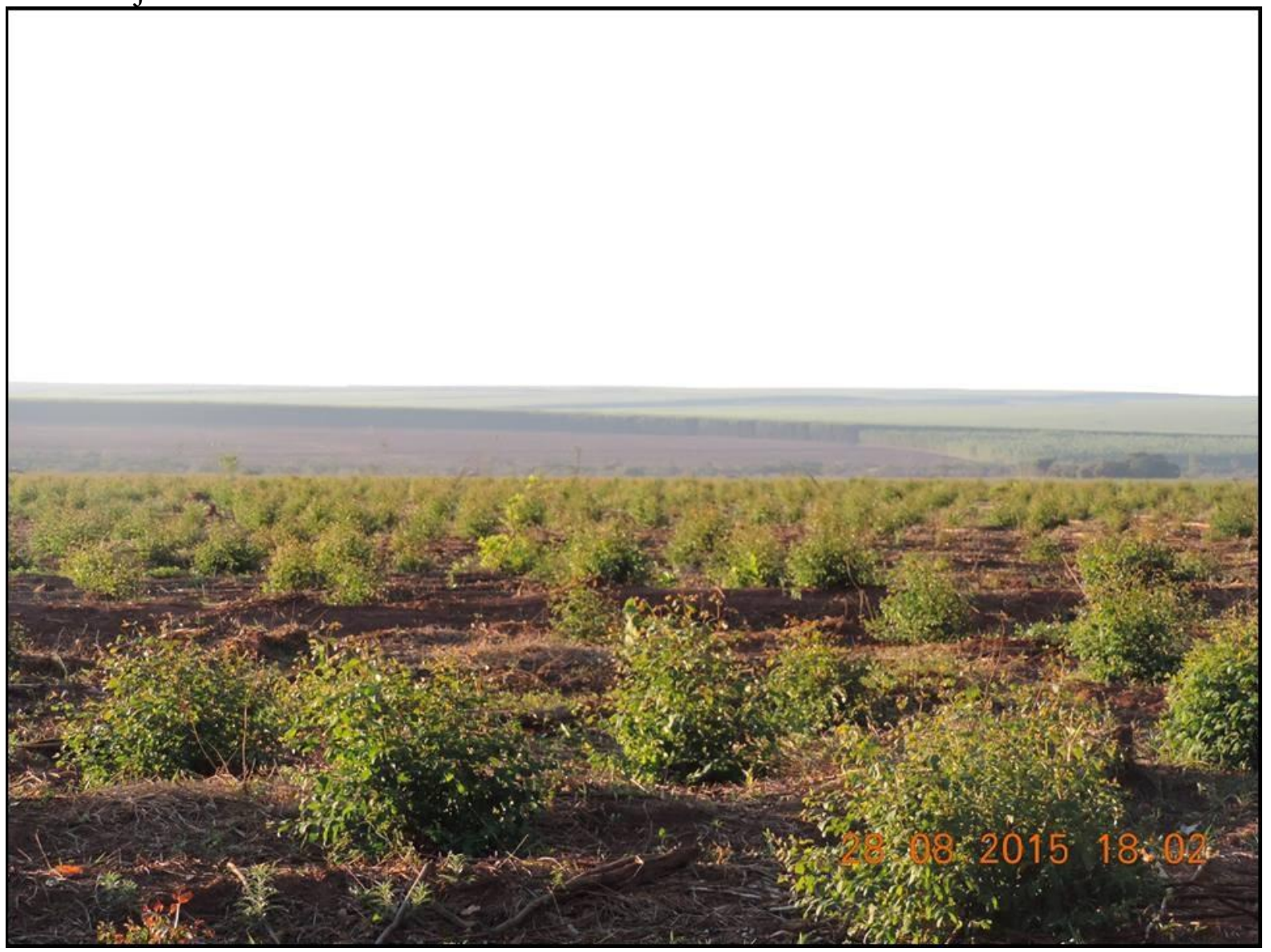

Fonte: Próprio autor, 2016.

\section{CONCLUSÃO}

As técnicas de sensoriamento remoto e geoprocessamento possibilitaram a geração dos mapeamentos de uso e cobertura da terra, se tornando úteis na obtenção e geração de todos os dados utilizados, através dos softwaeres ArcGis®10 e Spring 5.2.3 em um Sistema de Informação Geográfica, proporcionando um resultado satisfatório. Oferecendo informações essenciais para o mapeamento do uso e cobertura da terra, retratando a atual evolução do cultivo de eucalipto no município de Selvíria/BRASIL. 


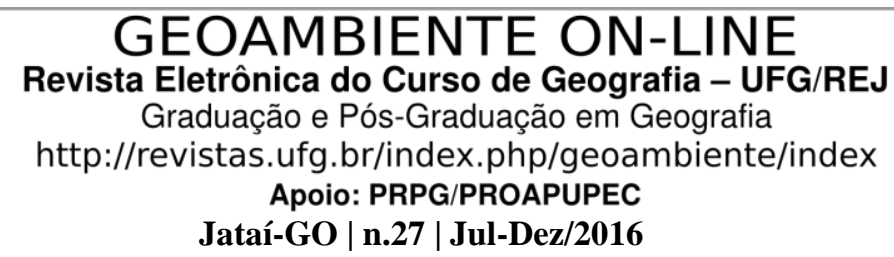

Nota-se que mesmo com a diminuição da pastagem, a mesma se mostrou dominante e grande parte dessa área é utilizada para pecuária. As áreas florestais vêm reduzindo sua área de acordo com que as atividades antrópicas vêm aumentando na região.

Concluiu-se que o município de Selvíria/BRASIL está se tornando um atrativo de grandes empresas para o cultivo de florestas plantadas, hoje contando com grandes empresas deste setor e de forma geral, esse cultivo tem adentrado várias áreas como de pastagens e florestais, no ano de 2000 e 2008 apenas plantações da empresa Fibria-MS Celulose Sul Mato-Grossense Ltda; estavam no local, mostrando assim, que a tendência é elevar as áreas destinadas à este cultivo, pois no ano de 2013 a empresa Florestal Investimentos Florestais S/A - Eldorado Brasil foi instalada no município de Três Lagoas/MS, o que proporcionou um aumento nas áreas plantadas na região.

\section{REFERÊNCIAS BIBLIOGRÁFICAS}

ALVES, A. M; PEREIRA, J. S; SILVA, N. A introdução e a expansão do eucalipto em Portugal. Universidade de Lisboa, Janeiro de 2007.

ARGÜELlO, F. V. P; BATISTA, G. T; PONZONI, F. J; DIAS, N. W. Distribuição espacial de plantios de eucalipto no trecho paulista da bacia hidrográfica rio Paraíba do Sul, SP, Brasil.

Revista Ambi-Agua, Taubaté, v. 5, n.3, p. 77-90, 2010.

ATLAS MULTIRREFERENCIAL. Governo do Estado de Mato Grosso do Sul - SEPLAN. IBGE, 1990.

BINKOWSKI, P. Conflitos ambientais e significativos sociais em torno da expansão da silvicultura de eucalipto na "metade sul” do Rio Grande do Sul. Porto Alegre, 2009. 212p.

COUTINHO, A. X. P. Curso de Silvicultura. Lisboa: Tipografia da Academia Real das Sciências. 1886.

ESRI 2011. ArcGIS Desktop: Release 10. Redlands, CA: Environmental Systems Research Institute.

GREGORY, Ken J. A natureza da geografia física. Rio de Janeiro: Bertrand Brasil, 1992.

IBGE. Instituto Brasileiro de Geografia e Estatística. Manual de uso e ocupação da terra.

Manuais Técnicos em Geociências. Brasil número 7. Brasília, 2013. 91p.

KUDLAVICZ, M. Dinâmica agrária e a territorialização do complexo celuloselpapel na microrregião de Três Lagoas/MS. 2011. 177f. Mestrado. Dissertação apresentada ao programa de pós-graduação em geografia. Três Lagoas, UFMS. 2011. 


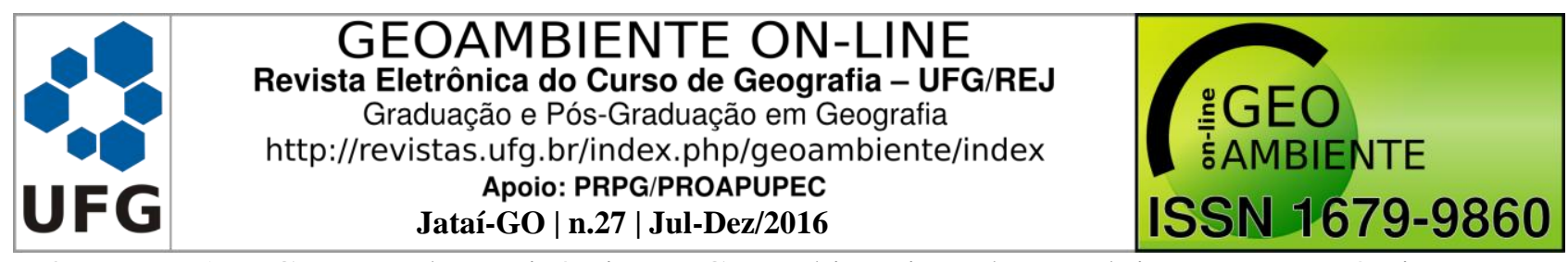

OLIVEIRA, G. H. de. Dinâmicas Geoambientais: desenvolvimento econômico e sustentabilidade ambiental. Revista Eletrônica da Associação dos Geógrafos Brasileiros Seção Três Lagoas-MS, nº15, p.152-153, 2012.

PIMENTEL, C. S. Eucalipto Globulus. Descrição, Cultura e Aproveitamento D’Esta Árvore. Lisboa: Typografia Universal, 1884.

PORTAL DO INVESTIDOR. Fundo 157. Disponível em: 〈http://www.investidor.gov.br/>. Acesso em: 15 mar. 2014.

PRYOR, L. D. The Biology of Eucalyptus. London: Edward Arnold, 1976.

RADICH, M. C. Uma exótica em Portugal. Revista Ler História, n 25, p 11-26. 1994.

SANTOS, R. F. dos (ORG.). Vulnerabilidade Ambiental - Desastres Naturais ou Fenômenos Induzidos. Brasília: MMA, 2007. 192 p.

SILVA, A.M. Tutorial de Spring. UFPR, João Pessoa, 2013. 41p.

SPRING. Integrating remote sensing and GIS by object-oriented data modelling. Camara G, Souza RCM, Freitas UM, Garrido J Computers \& Graphics, 20: (3) 395-403, May-Jun 1996. VITAL, M. H. F. Impactos Ambientais de Florestas de Eucalipto. Revista do BNDES, Rio de Janeiro, v. 14, n. 28, p. 235 - 276, dez. 2007. 